
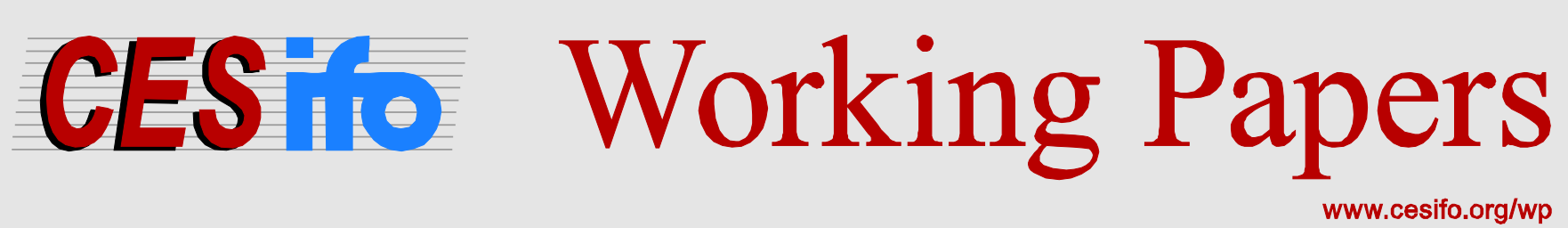

\title{
Is Marriage as Good as a Contract?
}

\author{
Alessandro Cigno
}

\section{CESIFO WORKING PAPER NO. 4555 \\ CATEgory 3: Social PROTECTION \\ DECEMBER 2013}

An electronic version of the paper may be downloaded

- from the SSRN website:

- from the RePEc website:

- from the CESifo website:

www.SSRN.com

Www.RePEc.org

www.CESifo-group.org/wp

\section{CESifo}




\title{
Is Marriage as Good as a Contract?
}

\begin{abstract}
Neither marriage nor a legally enforceable contract serves any useful purpose if the parties have access to a perfect credit market. In the presence of credit rationing, efficiency and utility equalization are guaranteed only by a legally enforceable contract. Separate-property marriage may reduce and community-property marriage actually eliminate inefficiency, but neither of them guarantees utility equalization.
\end{abstract}

JEL-Code: C780, J120, K360.

Keywords: contracts, hold-up problem, separate-property marriage, community-property marriage, divorce legislation.

\author{
Alessandro Cigno \\ University of Florence \\ Department of Economics and Management \\ Via delle Pandette 21 (D5) \\ Italy-50127 Florence \\ cigno@unifi.it
}

An earlier version of this paper was presented to the 2011 CESifo Conference on Law and Economics. Comments by discussant Mordechai E. Schwarz are gratefully acknowledged. 


\section{Introduction}

Marriage is not a contract. From a strictly legal point of view, it is essentially an agreement to submit to court adjudication if the union breaks down. Can it serve the same purpose as a freely negotiated and legally enforceable contract specifying the allocation of duties and the distribution of benefits between the parties? The early economics of the family literature does not address this question because it does not distinguish between married and unmarried couples. Even Gary Becker's seminal 1973 and 1974 articles, entitled "A theory of marriage", are not about marriage at all, because they model couple formation and dissolution under the assumption that the "spouses" can costlessly reoptimize every time a new matching opportunity presents itself.

The first economic analysis of marriage in the legal sense is Mnookin and Kornhauser (1979). Very much a lawyer's essay, that article uses game-theoretical concepts to show how being married conditions a couple's private bargaining. The second is Ch. 5 of Cigno (1991), where it is shown that divorce legislation may induce some couples to inefficiently divorce, and some others to inefficiently stay married. These themes come up again and again in the more recent literature. Clark (1999) shows how the allocation of legal rights within marriage affects the probability of divorce. Zelder (1993) shows that married couples may inefficiently divorce, and Fella et al. (2004) that they may inefficiently stay married. Scott (2002) and Wickelgren (2009) argue that marriage encourages couple-specific investments. Others, including Rowthorn (2002), and Chiappori and Oreffice (2008), argue that marriage improves the "match quality" of the union. Contracts are examined in Mechoulan (2005) and Rainer (2007).

The present paper shows that, given a perfect credit market, neither marriage nor a legally enforceable contract would serve any useful purpose. Contracts and marriage come into their own only if the credit market is imperfect. Section 2 of the paper sets out the analytical framework. Section 3 characterizes the behaviour of an unmarried couple with and without a legally enforceable contract. Section 4 examines the effects of marriage under different marital-property regimes. The legislative implications are briefly discussed in Section 5.

\section{Framework}

An essential ingredient of our reasoning is that forming a union allows the parties to produce local public goods without perfect market substitutes they could not otherwise. In general, such goods will include companionship and love as well as parenthood. Given our focus on mar- 
riage which in developed societies tends to coincide with the birth of the first child, however, we will consider only parenthood. For the same reason, we will eschew the economies-of-scale argument for communal living which applies to any group of persons and not just to potential parents. Another essential ingredient is that earning ability increases with labour experience or, equivalently, decreases without it. Evidence of returns to seniority and experience is reported by, among others, Buchinsky et al. (2005a and 2005b). Evidence that part-time work and career breaks reduce earning ability is reported by, among others, Phipps et al. (2001), Gupta and Smith (2002), Kunze (2002), Manning and Petrongolo (2008) and Beblo et al. (2009). The third ingredient is credit market imperfection, which may prevent a young person with good career prospects but insufficient assets from paying his or her companion at front, or posting a bond as suggested in Lommerud (1989), to stay at home and look after the children. The fourth is that the domestic division of labour is endogenous, and does not depend on gender.

Given that, at least in developed countries, social disapproval and legal discrimination of unmarried couples are on the wane, we assume that there is no exogenous penalty for unmarried cohabitation or exogenous bonus for marriage. Assuming the contrary would distract us from the task of determining whether marriage per se serves the same purpose as a freely negotiated and legally enforceable contract. Given also that, again in developed countries, marriage tends to occur after a period of search and unmarried cohabitation, we assume that the parties are perfectly informed about each other's characteristics, and about those of alternative partners. This assumption is extreme, but it will allow us to get to our point with a minimum of fuss. For the same reason, we will assume that there is no uncertainty about divorce court decisions. ${ }^{1}$ Income uncertainty will be touched upon in the concluding section. As in much of the existing literature, the couple's behaviour is modelled as a cooperative game, identified for simplicity with Nash-bargaining. Our story begins when a woman $f$ and a man $m$ have already sorted themselves into a couple, and have to decide whether or not to have a child. The question is whether there is any advantage for either or both parties in drawing up a a legally enforceable contract or formalizing the union through marriage. The analysis encompasses two periods, labelled 1 and 2. The child is dependent on the parents in period 1, an independent adult in period 2 .

Iyigun (2009) demonstrates the existence of a sorting equilibrium in which every agent is matched with one who has the same preferences.

\footnotetext{
${ }^{1}$ Couple behaviour under uncertainty about court sentencing is examined in Deffains and Langlais (2006).
} 
As our analysis starts where the matching process ends, we then assume that $f$ and $m$ have the same utility function,

$$
U_{i}=u\left(a_{i 1}\right)+u\left(a_{i 2}\right)+\beta v(c, t), 0<\beta<1, i=f, m
$$

where $a_{i 1}$ denotes $i$ 's consumption in period $1, a_{i 2} i$ 's consumption in period 2, $c$ the amount of money that the couple spends on the child in period 1 , and

$$
t=f\left(t_{f}, t_{m}\right)=f\left(t_{m}, t_{f}\right)
$$

an intermediate good ("attention") domestically produced with the time that either or both parents spend with the child in period 1. The functions $u(),. v($.$) and f($.$) are increasing and concave. We interpret v(c, t)$ as the child's lifetime utility conditional on the goods and attention received from the parents, and $\beta$ as a parental altruism parameter. Since $v(c, t)$ figures in the utility function of both parents, the child's wellbeing is a local public good. According to this formulation of the utility function, $f$ and $m$ are altruistic towards their child but not towards each other. So long as each party cares about its own consumption at least a little more than it cares about the other's, introducing mutual altruism would make little difference to the results. ${ }^{2}$

As leisure is not an argument of $U_{i}, i$ will throw any time it does not spend with the child inelastically on to the labour market. Normalizing to unity the total amount of time available to each party in each period, $i$ 's period-1 labour supplies will then be $L_{i}=1-t_{i}$ In period 2 , when the child no longer demands attention, the labour supply will be equal to unity for both parties. In period $1, i$ is endowed with $b_{i}$ units of a tradeable asset money, and commands a wage rate $w_{i}$. In period $2, i$ 's money holdings will be $r s_{i}$, where $s_{i} \geq 0$ is $i$ 's period- 1 savings and $r$ is the interest factor. His or her wage rate will be $w_{i}+w\left(L_{i}\right)$, where $w($. is an increasing function. Therefore, $i$ earns

$$
y_{i 1}=w_{i} L_{i}
$$

in period 1 , and

$$
y_{i 2}=w_{i}+w\left(L_{i}\right)
$$

in period 2 .

Masters (2008) shows that matches between equally attractive individuals are stable, and matches between unequally attractive ones are not. Identifying (somewhat prosaically) $i$ 's attractiveness with his or her maximized utility as a single, we will then assume that $\left(b_{f}, w_{f}\right)$ and

\footnotetext{
${ }^{2}$ For an analysis of this case, see Stark (1993).
} 
$\left(b_{m}, w_{m}\right)$ satisfy

$\max _{s_{i}}\left\{u\left(b_{i}+w_{i}-s_{i}\right)+u\left(w_{i}+w(1)+s_{i} r\right)\right.$ s.t. $\left.s_{i} \geq 0\right\}=U^{S}, i=f, m$,

where $U^{S}$ is the common value of this utility. That restricts the range

of admissible combinations of initial money holdings and initial earning ability, but still leaves scope for either positive or negative assortment over these two characteristics.

\section{Contracts}

A legally enforceable contract regulating the allocation of domestic duties and the size and direction of transfers between $f$ and $m$ may be viewed as the equilibrium of a Nash-bargaining game played before the child is born. Assuming that marriage is not an option, and that singlehood is the best alternative to the present match, ${ }^{3}$ the threat-point of the game is $\left(U^{S}, U^{S}\right)$. The contract then maximizes

$$
N=\left(U_{f}-U^{S}\right)\left(U_{m}-U^{S}\right)
$$

subject to

$$
F\left(U_{f}, U_{m}\right) \leq 0
$$

where $F\left(U_{f}, U_{m}\right)$ is the Utility Possibility Frontier (UPF). The latter is traced maximizing $U_{f}$ given $U_{m}$ (or $U_{f}$ given $U_{m}$ ), subject to the couple's budget and borrowing constraints,

$$
\begin{gathered}
a_{f 1}+c+s_{f}=b_{f}+y_{f 1}+x_{1}, \\
a_{m 1}+s_{m}+x_{1}=b_{m}+y_{m 1}, \\
a_{f 2}=s_{f} r+y_{f 2}+x_{2}, \\
a_{m 2}+x_{2}=s_{m} r+y_{m 2}, \\
s_{f} \geq 0
\end{gathered}
$$

and

$$
s_{m} \geq 0
$$

where $x_{1}$ denotes a money transfers (positive, negative or zero) from $m$ to $f$ in period 1 , and $x_{2}$ a similar transfer in period 2. Although the monetary cost of the child is conventionally assigned to $f$, the effective burden will fall, at least in part, on $m$ if $x_{1}$ or $x_{2}$ is positive.

\footnotetext{
${ }^{3}$ For our present purposes, there is no need to specify whether singlehood means that $f$ and $m$ never see each other, that they see each other but do not live together, or even that they live together but take care not to have children.
} 
At each point of the UPF, the allocation satisfies

$$
\begin{gathered}
\frac{u^{\prime}\left(a_{i 1}\right)}{u^{\prime}\left(a_{i 2}\right)}=r+\frac{\rho_{i}}{\mu_{i}}, i=f, m, \\
\frac{f_{t_{f}}\left(t_{f}, t_{m}\right)}{f_{t_{m}}\left(t_{f}, t_{m}\right)}=\frac{\frac{\partial y_{f 1}}{\partial \partial t_{f}}+\frac{\frac{\partial y_{f 2}}{\partial t_{f}}}{r+\frac{\rho_{f}}{\mu_{f}}}}{\frac{\partial y_{m 1}}{\partial t_{m}}+\frac{\frac{\partial y_{m 2}}{\partial t_{m}}}{r+\frac{\rho_{m}}{\mu_{m}}}} \\
\mu_{f}=\mu_{m}
\end{gathered}
$$

and

$$
\rho_{f}=\rho_{m},
$$

where $\mu_{f}$ and $\rho_{f}$ are the Lagrange-multipliers of, respectively, (7) and (9), and $\mu_{m}$ and $\rho_{m}$ those of (8) and (10).

Taken together with (13) - (14), (11) tells us that the Marginal Rate of Substitution (MRS) of future for present consumption will be equalized across the parties, and (12) that the Marginal Rate of Technical Substitution (MRTS) of paternal for maternal time in the production of parental attention will be equated to the ratio of their respective marginal opportunity-costs. If neither party is credit constrained $\left(\rho_{f}=\rho_{m}=0\right)$, the RHS of (11) will be equal to $r$, and the allocation will then be a Pareto optimum. Otherwise, the RHS will be greater than $r$, and the allocation will only be a local Pareto optimum (meaning that the domestic resource allocation is undominated by any other, but the rest of the economy is not at a Pareto optimum). As is common practice in game theory, we will say that the allocation is efficient in both cases.

Using (1) - (2), we can re-write (12) as

$$
\frac{f_{t_{f}}\left(t_{f}, t_{m}\right)-\frac{w^{\prime}\left(1-t_{f}\right)}{r+\frac{\rho_{f}}{\mu_{f}}}}{f_{t_{m}}\left(t_{f}, t_{m}\right)-\frac{w^{\prime}\left(1--_{m}\right)}{r+\frac{\rho_{m}}{\mu_{m}}}}=\frac{w_{f}}{w_{m}} .
$$

This tells us that there is a unique $\left(w_{f} / w_{m}\right)$ ratio such that it will be efficient for $f$ and $m$ to take equal shares in the care of the children and thus also in market work. Viewing the $\left(w_{f}, w_{m}\right)$ pair as a random draw from a distribution satisfying (3), the probability that $f$ 's and $m$ 's initial earning abilities will be in that particular ratio is obviously zero. For any other $\left(w_{f} / w_{m}\right)$ ratio, efficiency will require some division of labour, ${ }^{4}$

\footnotetext{
${ }^{4}$ Nothing of substance changes if we allow $f$ and $m$ to differ not only in their abilily to raise money but also in their ability to raise children, or assume that not only the former but also the latter increases with experience; see Cigno (2007).
} 
and the contract will then stipulate which party (henceforth "the main earner") will have to specialize in market, and which (henceforth "the main childcarer") in domestic work. If $\left(w_{f} / w_{m}\right)$ is lower than the LHS of (15) at the equal-shares point, $f$ will be the main childcarer, and $m$ the main earner. Otherwise, $f$ will be the main earner, and $m$ the main childcarer.

Given that the efficiency locus is symmetrical around the $45^{\circ}$ line on the $\left(U_{f}, U_{m}\right)$ plane, and that the UPF coincides with the efficiency locus, the Nash-bargaining equilibrium will assign the same utility to both parties,

$$
U_{i}=U^{*}, i=f, m \text {. }
$$

irrespective of who is the main childcarer and who the main earner.

In reality, only a small minority of couples negotiates a legally enforceable contract. Indeed, not all contracts are legally enforceable even in the business sphere. Macaulay (1963) reports that some contracts are deliberately designed not to be legally enforceable. Ryall and Sampson (2009) find that some are legally unenforceable because the parties explicitly wave their rights to court adjudication in case of dispute. The reason for this reluctance to enter into water-tight contracts is that they are not only expensive to draw-up, but also expensive to enforce. In the sentimental sphere, there is an extra reason, namely that the punctilious enumeration, at the very outset of a union, of each party's potential misdeeds and attendant penalties would likely kill even the most promising of relationships stone dead.

In the absence of a contract, and continuing to assume that marriage is not an option, the main earner's promise to make the main childcarer a transfer in the next period will not be credible, because it is not be in the main earner's interest to honour it. Therefore, $x_{2}$ is constrained to be zero, and (13) - (14) need not hold. That would not matter if credit were not rationed, because the MRS would then be equalized across the parties anyway. It may matter if credit is rationed, however, because the MRS may not then be equalized across the parties.

Suppose, for example, that $f$ is the main childcarer (but analogous results apply if $m$ is). Suppose also that $0 \leq \rho_{f}<\rho_{m}$ for any $x_{1}>0$. For $x_{1}$ sufficiently small, $U_{f}<U_{m}, \mu_{f}>\mu_{m}, r+\frac{\rho_{f}}{\mu_{f}}<r+\frac{\rho_{m}}{\mu_{m}}$ and the allocation is inefficient. At higher levels of $x_{1}, U_{f}$ will be closer to $U_{m}$, and $\mu_{f}$ to $\mu_{m}$, but $\rho_{f}$ will be further away from $\rho_{m}$ because $f$ 's borrowing constraint will be no tighter, and $m$ 's tighter than at the lower level of $x_{1}$. As $x_{1}$ increases, the marginal opportunity-cost of $U_{f}$ in terms of $U_{m}$ will then rise faster than it would if $x_{2}$ were not constrained to zero. Consequently, the UPF will lie inside the efficiency locus, and not be symmetrical around the $45^{\circ}$ line. If a Nash-bargining equilibrium exists 
(i.e., if $\left.F\left(U^{S}, U^{S}\right)<0\right)$, it will then be inefficient and give the main childcarer less utility than the main earner. But it is also possible that such an equilibrium does not exist (i.e., that $F\left(U^{S}, U^{S}\right)>0$ ). We have then the classical hold-up problem.

Proposition 1. In the absence of credit rationing, the couple will reach an agreement regarding the allocation of domestic duties and the distribution of consumption before a child is born. That agreement will be efficient and give both parties the same utility. If the main earner is credit constrained, however, an agreement will be reached only if it is legally enforceable. Otherwise, either there will be no agreement, or the agreement will be inefficient and give a party more utility than the other.

\section{Marriage}

Would it make a difference if the couple were to marry? Marriage is not a legally enforceable contract. ${ }^{5}$ From a legal point of view, it only commits the parties to ask for court permission if either or both of them want to terminate the arrangement ("divorce"), and to submit to the court's decisions regarding division of assets and compensatory payments if such permission is granted. ${ }^{6}$ We will assume that divorce is always granted on the payment of a positive fee $\gamma$, and that the court will order $m$ to hand over to $f$ a sum $\theta$ (positive, negative or zero) in addition to her half-share of any property they might hold in their joint names. ${ }^{7}$ If the courts (or the legislator) have a neutral stance,

$$
\theta \equiv 0
$$

If they have an egalitarian stance,

$$
\theta=\theta\left(U_{m}-U_{f}\right), \theta(0)=0, \theta^{\prime}\left(U_{m}-U_{f}\right)>0 .
$$

We can safely disregard the possibility that a court would deliberately set out to increase inequality between the former spouses. As it remains

\footnotetext{
${ }^{5}$ It does not specify who should do what, and even the reciprocal promise to live together and be sexually faithful to each other is no more than a statement of intent. There are no legal penalties for breach of promise while the marriage lasts.

${ }^{6}$ For a general discussion of divorce and marital property legislation from an economic point of view, see Mechoulan (2005).

${ }^{7}$ In most western legislations, infidelity nor disertion are not necessary to obtain a divorce, and do not affect the level and direction of the compensation that may be ordered by the court if the divorce is granted.
} 
true that neither party can have an interest in ending the union before period 2, $\theta$ cannot be construed as child maintenance.

Suppose that a legally enforceable contract is not an option for the reasons outlined in the last section. If, as may well be case, no unmarried Nash-bargaining equilibrium exists, the threat-point of the married game will be $\left(U^{S}, U^{S}\right)$. Otherwise, it will be $\left(U_{f}^{0}, U_{m}^{0}\right)$, where $U_{f}^{0} \neq U_{m}^{0}<U^{*}{ }^{8}$ The shape of the UPF will depend on whether the couple is married in a separate-property, or in a community-property jurisdiction. In the former, any income produced or assets acquired by either party at any time are that party's individual property. In the latter, any income produced or assets acquired after the marriage are the couple's joint property.

With separate-property marriage, the budget and borrowing constraints are (5) - (10) as if the couple were not married. To allow for the possibility that marriage will lend credibility to the main earner's promise to compensate the main childcarer in period 2 rather than 1 , however, we do not restrict $x_{2}$ to be zero. On the other hand, however, we now have the additional restriction that, in equilibrium, neither party can be better-off divorced than married,

$$
s_{f} r+y_{f 2}+\theta-\gamma \leq a_{f 2}
$$

and

$$
s_{m} r+y_{m 2}-\theta-\gamma \leq a_{m 2} .
$$

We will refer to these inequalities as the divorce-threat constraints. Notice that at most one of them can be binding, and that neither of them will be if the courts have a neutral stance or $\gamma$ is sufficiently large. Therefore, separate-property marriage can make a difference only if the courts are egalitarian, and the cost of obtaining a divorce is not prohibitively high. That is what we will assume.

At each point of the UPF,

$$
\frac{u^{\prime}\left(a_{i 1}\right)}{u^{\prime}\left(a_{i 2}\right)}=r+\frac{\rho_{i}}{\mu_{i}-\xi_{i}}, i=f, m
$$

and

$$
\frac{f_{t_{f}}\left(t_{f}, t_{m}\right)}{f_{t_{m}}\left(t_{f}, t_{m}\right)}=\frac{\frac{\partial y_{f 1}}{\partial \partial t_{f}}+\frac{\frac{\partial y_{f 2}}{\partial t_{f}}}{r+\frac{\rho_{f}}{\mu_{f}-\xi_{f}}}}{\frac{\partial y_{m 1}}{\partial t_{m}}+\frac{\frac{\partial y_{m} 2}{\partial t_{m}}}{r+\frac{\rho_{m}}{\mu_{m}-\xi_{m}}}}
$$

${ }^{8}$ As already noted, if the unmarried equilibrium were efficient and gave the same utility to both parties $\left(U_{f}=U_{m}=U^{*}\right)$, there would be no point in marrying. 
where $\xi_{i}$ denotes the Lagrange-multiplier of $i$ 's divorce-threat constraint $(i=f, m)$. If credit is not rationed $\left(\rho_{f}=\rho_{m}=0\right)$, it is clearly irrelevant whether the couple is or is not married. If the main earner is credit constrained, however, marriage may make the allocation less inefficient than it would be without marriage. Suppose again that $f$ is the main childcarer (but analogous results again apply if $m$ is). Suppose once more that $0 \leq \rho_{f}<\rho_{m}$ for any $x_{1}>0$, and that $\mu_{f}>\mu_{m}$ and $U_{f}<U_{m}$ if $x_{1}$ is sufficiently small and $x_{2}=0$. If $f$ can credibly threaten divorce $\left(\xi_{f}>0, \xi_{m}=0\right)$, her intertemporal trade-off will then be closer to his than it would be without marriage $\left(\xi_{f}=\xi_{m}=0\right)$.

With separate-property marriage, therefore, the distortion caused by the main earner's borrowing constraint is traded-off against that caused by the main childcarer's divorce-threat constraint. The intuition is that, if a divorce would be against the main earner's interest, the main childcarer can safely accept to be compensated, at least in part, in period 2 rather than 1. Given that, with separate-property marriage, neither the UPF nor the threat-point of the Nash-bargaining game are the same as with a contract, there is no reason to expect that the utility distribution will.

With community-property marriage, the couple faces the joint budget and borrowing constraints,

$$
\begin{gathered}
a_{f 1}+a_{m 1}+n c+s=b_{f}+b_{m}+y_{f 1}+y_{m 1} \\
a_{f 2}+a_{m 2}=s r
\end{gathered}
$$

and

$$
s \geq 0
$$

where $s$ is the couple's joint savings.

The divorce-threat constraints are now

$$
\left(b_{f}+z\right) r+y_{f 2}+\frac{p}{2}+\theta-\gamma \leq a_{f 2}
$$

and

$$
\left(b_{m}-z\right) r+y_{m 2}+\frac{p}{2}-\theta-\gamma \leq a_{m 2},
$$

where $z$ denotes a voluntary transfer (positive, negative, or zero) from $m$ to $f$ in period 1 , and

$$
p \equiv\left[s-\left(b_{f}+b_{m}\right)\right] r
$$

is the couple's period-2 community property. Once again, at most one of the divorce-threat constraints can be binding, and neither of them will if $\gamma$ is sufficiently large. Notice, however, that the party who can credibly 
threaten divorce is not necessarily the main childcarer as in separateproperty marriage. There is now a distinct possibility that the threat can be wielded by the main earner, who has smaller pre-marital assets and can expect to receive more than half of $p$ in the event of divorce.

As the only way either party can now make a transfer to the other is by drawing on the assets it had before marriage,

$$
-z \leq b_{f}
$$

and

$$
z \leq b_{m}
$$

At most one of these asset-disposal constraints will be binding.

At each point of the UPF,

$$
\begin{gathered}
\frac{u^{\prime}\left(a_{i 1}\right)}{u^{\prime}\left(a_{i 2}\right)}=\frac{\mu r+\rho}{\mu-\xi_{i}}=r+\frac{\rho}{\mu-\xi_{i}}, i=f, m, \\
\frac{f_{t_{f}}\left(t_{f}, t_{m}\right)}{f_{t_{m}}\left(t_{f}, t_{m}\right)}=\frac{\frac{\partial y_{f 1}}{\partial t_{f}}+\frac{\frac{\partial y_{f 2}}{\partial t_{f}}}{r+\frac{\rho}{\mu-\xi_{f}}}}{\frac{\partial y_{m 1}}{\partial t_{m}}+\frac{\frac{\partial y_{m}}{\partial t_{m}}}{r+\frac{\rho}{\mu-\xi_{m}}}}
\end{gathered}
$$

and

$$
\xi_{f}-\xi_{m}=\zeta_{f}-\zeta_{m}
$$

where $\mu$ is the Lagrange-multiplier of (22), $\rho$ that of $(23), \xi_{f}$ and $\xi_{m}$ those of (24) and (25), and $\zeta_{f}$ and $\zeta_{m}$ those of (26) and (27). If $\rho=0$, the allocation is again efficient. Otherwise, it will be efficient if $\xi_{f}=\xi_{m}=0$, which in view of (30) implies $\zeta_{f}=\zeta_{m}=0$. Intuitively, the reason why the divorce threat makes things worse (rather than better as in the case of separate-property marriage) is that there is no credit-induced distortion to be traded-off against the one induced by the divorce threat. If the party who would suffer from the divorce voluntarily transfers enough of its pre-marital assets to the one who would gain from it to make the latter desist, however, that will make the allocation efficient, and both parties better-off. ${ }^{9}$ That will be possible, however, only if the former has sufficient premarital assets to transfer. If not, the equilibrium will be inefficient. Either way, there is no guarantee that the married equilibrium will assign the same utility to both parties (in the efficient case because the UPF is symmetrical but the threat-point may be asymmetrical, in the inefficient one because the UPF is asymmetrical).

\footnotetext{
${ }^{9}$ This argument is consistent with Rainer (2007).
} 
Proposition 2. Marriage can make a difference only if credit is rationed, the cost of obtaining a divorce is not prohibitively high, and the courts aim to reduce utility inequality between the former spouses in the event of divorce. Separate-property marriage may make the domestic resource allocation less inefficient, and community-property marriage may make it efficient, but neither form of marriage guarantees utility equalization across the spouses.

\section{Concluding remarks}

If the parties had access to a perfect credit market, they could always reach an agreement about the allocation of duties and the distribution of benefits without any need for a legally enforceable contract because any compensatory transfer could be made at front. This agreement would be efficient and give the same utility to both parties. Without a perfect credit market, however, the parties may not reach an agreement even though it would be in their interest to do so (the hold-up problem). If they do, it will be inefficient and give one party more utility than the other. In such circumstances, efficiency and utility equalization would be guaranteed only by a legally enforceable contract. Short of that, separate-property marriage may reduce and community-property marriage actually eliminate inefficiency, but neither form of marriage ensures utility equalization. Although community-property marriage may actually achieve efficiency while separate-property marriage can only get closer to it, the former is not superior to the latter in all circumstances. First, because community property is beneficial only if the parties have sufficient pre-marital assets (therefore, the young and impecunious might be better served by separate property). Second, because our results are derived under the assumption that incomes are certain. If either or both parties are at risk of bankruptcy, it may be in the couple's common interest not to hold assets in their joint names. The legislator should thus allow couples to choose the matrimonial property regime. In Italy, where there is such a choice, a minority opts for separate-property marriage despite fiscal inducements to opt for community property.

\section{References}

Beblo, M., S. Bender and E. Wolf (2009), "Establishment Level Wage Effects of Entering Motherhood", Oxford Economic Papers 61, i11-i34

Becker, G. S. (1973), "A Theory of Marriage: Part I", Journal of Political Economy 81, 813-846 
Becker, G. S. (1974), "A Theory of Marriage: Part II," Journal of Political Economy 82, S11-S26

Buchinsky, M. D. Fougère, F. Kramarz and R. Tchernis (2005a), "Interfirm Mobility, Wages, and the Returns to Seniority and Experience in the U.S.", IZA DP 1521

Buchinsky, M. D. Fougère, T. Kamionka and R. Tchernis (2005b),"The Returns to Seniority in France (and Why Are They Lower than in the United States?)", IZA DP 1935

Chiappori, P. A. and S. Oreffice (2008), Birth Control and Female Empowerment: An Equilibrium Analysis, Journal of Political Economy $116,113-140$

Cigno, A. (1991), Economics of the Family, Oxford and New York: Clarendon Press and Oxford University Press

Cigno, A. (2007), "A Theoretical Analysis of the Effects of Legislation on Marriage, Fertility, Domestic Division of Labour, and the Education of Children", CESifo WP 2143

Clark, S. (1999), "Law, Property, and Marital Dissolution", Economic Journal 109, C41-C54

Deffains, B. and E. Langlais (2006), "Incentives to Cooperate and the Discretionary Power of Courts in Divorce Law", Revue of Economics of the Household 4, 423-439

Del Boca, D. and C. Flinn (1995), "Rationalizing Child Support Orders", American Economic Review 85, 1241-1262

Gupta, N. D. and N. Smith (2002), "Children and Career Interruptions: the Family Gap in Denmark", Economica 69, 609-629

Iyigun, M. (2009), Marriage, Cohabitation and Commitment, IZA DP 4341

Kunze, A. (2002), The Timing of Careers and Human Capital Depreciation, IZA DP 509

Lommerud, K. E. (1989), Marital Division of Labor with Risk of Divorce. The Role of Voice Enforcement of Contracts", Journal of Labor Economics 7, 113-127

Macaulay, S. (1963), "Non-Contractual Relations in Business: A Preliminary Study, American Sociological Review 28, 55-67

Manning, J. and B. Petrongolo (2008), "The Part-Time Pay Penalty for Women in Britain", Economic Journal 118, F28-F51

Masters, A. (2008), "Marriage, Commitment and Divorce in a Matching Model with Differential Aging", Review of Economic Dynamics 11, 614-628

Mechoulean, S. (2005), "Economic Theory's Stance on No-Fault Divorce", Revue of Economics of the Household 3, 337-359 
Mincer, J. and H. Ofek (1982), "Interrupted Work Careers: Depreciation and Restoration of Human Capital", Journal of Human Resources $17,3-24$

Mnookin, R. H. and L. Kornhauser (1979), "Bargaining in the Shadow of the Law: The Case of Divorce", Yale Law Journal 88, 950-997

Phipps, S., P. Burton and L. Lethbridge (2001), In and Out of the Labour Market: Long-Term Income Consequences of Child-Related Interruptions in Women's Paid Work, Canadian Journal of Economics 34, 411- 429

Rainer, H. (2007), Should We Write Pre-Nuptial Contracts? European Economic Review 51, 337-363

Rowthorn, R. (2002), "Marriage as a Signal" in A. Dnes and R. Rowthorn, eds., The Law and Economics of Marriage and Divorce. Cambridge: Cambridge University Press

Ryall, M. D. and R. C. Sampson (2009), "Formal Contracts in the Presence of Relational Enforcement Mechanisms", Management Science $55,906-925$

Scott, E. (2002), "Marital Commitment and the Legal Regulation of Divorce" in A. Dnes and R. Rowthorn, eds., The Law and Economics of Marriage and Divorce. Cambridge: Cambridge University Press

Stark, O. (1993), "Nonmarket Transfers and Altruism", European Economic Review 37, 1413-1424

Wickelgren, A. L. (2009), "Why Divorce Laws Matter: Incentives for Non-Contractible Marital Investments Under Unilateral and Consent Divorce", Journal of Law, Economics and Organization 25, 80-106

Zelder, M. (1993), "Inefficient Dissolutions as a Consequence of Public Goods: The Case of No-Fault Divorce", Journal of Legal Studies 22, 503-520 